\title{
INTEGRATION INTO THE SCHOLARLY COMMUNITY AND PHD IMPOSTER SYNDROME: DOCTORAL EDUCATION QUALITY ASSURANCE ASPECTS
}

\author{
Boychuk P. M., Fast O. L., Martyniuk A. P.
}

\section{INTRODUCTION}

In the XXI century, investments in people, in their professional development and education in general play a priority role in preventing the crisis of science and ensuring the competitive advantages of higher education in Ukraine and the world. Of particular importance in the global educational space is the modernization of the third cycle of higher education - doctoral training (English Doctoral education, $\mathrm{PhD}$ training, Doctorate). It is obvious that in the context of new globalization challenges and the "stage of turbulence" in education, the importance of a holistic and systematic study of ways to manage the quality of doctoral training is undeniable.

\section{Doctoral Candidates' Imposter Syndrome}

Academic settings in higher education can trigger impostor phenomenon (Knights \& Clarke, 2014). Particularly, graduate training challenges include the transition between dependent and independent phases when students shift from coursework and supervised research to working more independently (Lovitts, 2008). Successful graduate training involves developing higher-order thinking/reasoning and scientific communication skills that are rather complex (Lovitts, 2005). Developing these skills requires psychosocial support (Etzkowitz et al., 2000) and constructive and supportive supervisory relationships that also contribute to doctoral satisfaction (Pyhältö \& Keskinen, 2012). Other challenges include the lack of diversity and equity in many fields, a long and undefined completion time (Pitchforth et al., 2012), first-generation status (Gardner, 2013), and maintaining a critical mass of diverse students (Allen-Ramdial \& Campbell, 2014), among others. A comprehensive 
literature review from four decades of research identified six primary areas of challenges in doctoral training:

- lack of teaching training for doctoral students,

- program design issues including funding and a lack of standardized assessment policy,

- inadequate training in academic writing and research,

- fewer career advancement opportunities post $\mathrm{PhD}$ completion,

- non-standardized supervisory practices,

- unwarranted experiences such as isolation, discrimination, and reduced motivation to complete doctoral training (Jones, 2013).

Other challenges could include factors like low self-confidence, isolation, and lack of belonging that are a barrier for integrating and thriving in one's department or field (Carlone \& Johnson, 2007; Russell \& Atwater, 2005). The nature and number of graduate school challenges one could face are multiple, complex, and many graduate students experience mental health issues as a result during training (Evans et al., 2018; Levecque et al., 2017). The stress, burnout, and sense of not belonging in graduate school could manifest as the impostor phenomenon due to the perception that one lacks ability (Burt et al., 2017).

To understand some of these challenges, it would be worthwhile to examine research on what motivates people to act or be a particular way. Herzberg, Mausner, and Snyderman (1959) developed a two-factor model of motivation where job satisfaction is determined by factors related to the content of the job and one's relationship to it, such as achievement, receiving recognition, the nature of work, roles and responsibilities undertaken, and advancement opportunities. However, there are other factors related to an individual's relationship with the environment (and not job content), the absence of which may create dissatisfaction but the presence of which alone may not guarantee satisfaction (such as salary, security, safe work conditions). Other research has focused on developing organizations and work relationships that focuses on the development of emotional intelligence as a way to enhance individual- and group-level well-being (Adler \& Fagley, 2005).

In the empirical literature, well-being in doctoral students often lacks an operational definition, with researchers relying largely on participants' interpretation of the concept (e.g., Trenberth, 2005; 
University of California, Berkeley, 2014), thus posing an obstacle to the generalizability of existing findings. Some consistencies in well-being definitions across existing studies with doctoral students include maladaptive levels of stress (Wyatt \& Oswalt, 2013), mental-health concerns (e.g., depression), suicidal ideation (University of California, Berkeley, 2005), and physical health problems (e.g., upper respiratory infections; Juniper, et al., 2012) resulting from doctoral program demands. Thus, empirical efforts to date have shown doctoral students to demonstrate various psychological and physical concerns during their studies. Recent review articles focusing on doctoral students' wellbeing provide critical insight into some of the elements that shape the psychological experiences of students in their programs.

Based on a review of 163 empirical articles on doctoral students' well-being, Sverdlik et al. (2018) identified seven main factors that shape doctoral well-being. These factors include both external factors such as supervision, personal/social lives, departmental structures, and financial opportunities, as well as factors that are internal to the students including motivation, writing skills and strategies, and the development of an academic identity.

The authors suggest that in order to understand some of the processes involved in shaping the well-being of doctoral students, researchers are advised to explore both external (e.g., social) and internal (e.g., motivational) factors in a single model. These recommendations were further supported by Schmidt and Hansson (2018), who found triggers of psychological distress in doctoral students to be both external (e.g., perceived departmental/faculty support) and internal (e.g., passion toward one's area of research) in nature. Related work on the prevalence of well-being concerns in doctoral students by Pallos et al., (2005) investigated the well-being of 219 doctoral students from 12 universities in Tokyo, Japan. Findings showed 53\% of students to suffer from emotional disturbances, which consisted of anxiety and insomnia (accounted for $29 \%$ of the total variance), social dysfunction (10.9\% of the variance), symptoms of depression (5.9\% of the variance), and feelings of incompetence (5.2\% of the variance). These results corroborate that both interpersonal (e.g., social dysfunction) and intrapersonal (e.g., feelings of incompetence) factors are important to 
examine when trying to gain a comprehensive understanding of the determinants of wellbeing in doctoral students. A more recent report on doctoral students' well-being by the University of California, Berkeley (2014) found $47 \%$ of doctoral students across the disciplines to be depressed (as compared to $15 \%$ in the general population in the Americas; World Health Organization, 2017). With respect to differences between disciplines, Berkeley students enrolled in Arts \& Humanities programs reported the highest depression rates $(64 \%$ of students at depression threshold) as compared to $43-46 \%$ in the biological, physical, and social sciences, while law, social sciences, business students reported the "lowest" depression rates (37\%, 34\%, 28\%, respectively). Similarly, research by El-Ghoroury et al. (2012) with 387 American doctoral students showed $68.1 \%$ to report that their daily functioning was disrupted due to stress resulting from their academic pressures and responsibilities.

A recent article by Sverdlik and Hall (2019) provides further insight into the determinants of stress by demonstrating that in a sample of 3004 North American doctoral students, stress was found to be highest during the comprehensive/qualifying examination phase1, while being lowest during the coursework phase. The authors suggest that this is perhaps due to the increases in isolation and lack of structure that students face during the comprehensive examination phase, as compared to the group work and externally-structured tasks that are common to many graduate courses. The previously discussed quantitative findings are consistent with a large body of qualitative literature on doctoral education in which maladaptive indicators of well-being (e.g., stress, depression, low life satisfaction) are consistently uncovered but are not being addressed on a larger scale due to small sample sizes and their anecdotal nature (Brailsford, 2010).

Although some stress is expected during the doctoral process due to the challenging and intensive nature of doctoral education, these qualitative studies highlight that doctoral students often experience maladaptive levels of stress and other psychological concerns (e.g., depression) that interfere with daily functioning and can lead to longterm psychological suffering. Furthermore, even when students can identify coping strategies to improve their well-being (social interaction, 
exercise, engaging in hobbies, etc.), they often report being unable to engage in such strategies due to the demands of their doctoral programs. For example, $71 \%$ of participants in the University of California, Berkeley study (2014) reported a lack of time and $47 \%$ reported financial constraints as major obstacles to participating in any recreational activities. Taken together, findings on doctoral students' well-being to date highlight the grim psychological experiences of these students, as well as some hurdles that students face when attempting to use coping strategies to improve these experiences.

Another obstacle to improving the well-being of doctoral students is that the determinants of wellbeing among these students are not well understood. According to Di Pierro (2007), "at the heart of doctoral students' struggling lie serious concerns that challenge the notions of certainty that they are indeed worthy of embarking upon doctoral study" . This assertion was supported by a comprehensive review of the doctoral education literature (Sverdlik et al., 2018) that identified selfworth and self-efficacy as important contributors to doctoral students' well-being. Furthermore, qualitative studies on the development of doctoral students' academic identities (i.e., perceptions of one's academic competencies) underscore the prevalence of students experiencing maladaptive self-perceptions and reveal such perceptions to be closely tied to a sense of isolation from their departmental and/or scholarly communities. It is thus not surprising that much of the research on the development of an academic identity in doctoral students explores identity development as a function of a sense of belonging to the academic community (Emmioglu et al., 2017), usually in the context of specialized activities such as academic writing (Inouye \& McAlpine, 2019). McAlpine and Amundsen (2009) further suggest that students' academic identity is best conceptualized as having both individual and social aspects, with the former evolving primarily through academic work (e.g., writing research manuscripts) and involves perceptions of oneself as an academic, and the latter emerging over time as students

${ }^{1}$ Di Pierro, M. (2007). Excellence in doctoral education: Defining best practices. College Student Journal, 41(2), p. 370. https://pdfs.semanticscholar.org/d50b/721b1c2a 7 c0689ff80a84ea2392cf7f1abb8.pdf 
engage with their academic communities (e.g., research groups) and begin to find their unique role within these communities. Much of the struggle that doctoral students face, according to the authors, is establishing a sense of their own worth and efficacy with respect to the development of their personal competencies, as well as how they 'fit' within their academic community.

One lens through which doctoral students' negative self-perceptions can be understood is referred to as imposter syndrome. Imposter syndrome (Clance, 1985) is characterized by an inability to internalize one's own academic success, attributing any success to external factors (e.g., luck, networking) as well as a fear of not being able to repeat successful outcomes and a fear of being exposed as a "fraud." Individuals struggling with imposter syndrome will thus tend to attribute their achievement to a lowering of standards, timing of opportunities, or personal charm, and will focus their efforts on maintaining what they believe to be a very positive but very false impression of themselves. Their efforts are thus geared toward impression management, and they avoid new and challenging opportunities due to a fear of failure (Parkman, 2016). Thus, imposter syndrome represents a particularly relevant construct as it captures both negative perceptions of self-worth as a doctoral student (such as that they obtained their position by chance/luck and are therefore not worthy of it), as well as distorted views of one's abilities (e.g., success as a result of circumstances rather than efforts). In fact, research on imposter syndrome in doctoral students shows imposter syndrome to be negatively associated with both research self-efficacy and academic self-concept, defined as the self-assessment of one's academic abilities.

Impostor phenomenon correlates with the fear of isolation, lack of motivation, questioning one's intelligence (Stone et al., 2018), and feelings of inadequacy, among others. The impostor phenomenon is generally experienced across all genders, although marginalized groups including women and racial/ethnic minorities are particularly vulnerable (Peteet, Montgomery, \& Weekes, 2015) and historically underrepresented in many science, technology, engineering, and mathematics (STEM) disciplines. Those experiencing the impostor phenomenon in graduate school have attributed it to one's good luck and ability to pretend as well as other's 
kindness and poor judgment of skills (Chakraverty, 2019). Despite a growing body of research on its implications, our understanding about its triggers, typical duration is limited.

One notable aspect of imposter syndrome is the over-estimation of the abilities of others and underestimation of the effort required for others' successes (Parkman, 2016). Thus, when doctoral students are isolated from their academic communities, their evaluations of the efforts necessary for scholarly achievements (e.g., scholarly dissemination, winning research grants) become additionally skewed as they do not witness the work required for such achievements. When students are integrated into their communities, on the other hand, they are more involved in the work performed by community members and have a deeper understanding of the academic standards, as well as the efforts and skills required to meet those standards. Finally, doctoral students' sense of belonging to their scholarly community is closely related to feeling like a valued, involved, an integral part of that community and, therefore, an academic. The relationship between imposter syndrome and psychological health (e.g., depression) in the general population has been primarily explored in professional contexts (e.g., workplaces) and has been demonstrated in numerous studies. In higher education, this association between the imposter syndrome and poor mental health, including anxiety, depression, and burnout, has been demonstrated in undergraduate students (Sonnak \& Towell, 2001), postdoctoral trainees (e.g., Chakraverty, 2020), and medical residents . Although this research in academic domains has addressed the correlates and consequences of imposter syndrome, it has largely overlooked any possible antecedents of the phenomenon (such as perceived belongingness).

Among doctoral students, the imposter phenomenon has been extensively discussed in the public domain as a potentially salient determinant of students' well-being, but it has not received an equal amount of empirical attention. Of the limited existing research conducted to date on imposter phenomenon in doctoral students, studies have focused mainly on the experiences of women and uncovered trends related to fear of being exposed an imposter as well as a lack of perceived membership within their academic community. Recent research on the imposter phenomenon in doctoral students also highlights 
students' sense of doubt regarding the legitimacy of their position within their doctoral programs and the associated anxiety of being "exposed", as well as the extent to which a lack of perceived membership within one's academic community may exacerbate these beliefs (Jöstl et al., 2012). In sum, imposter syndrome appears to be a potentially important construct to understand in the context of doctoral education as it has been consistently found to be associated with mental health concerns in higher education in general and in doctoral programs in particular, and has been informally highlighted by the students themselves as a factor influencing their mental health. Furthermore, recent findings on this construct have implicated perceived belongingness as a possible social-environmental contributor to imposter syndrome, therefore suggesting that doctoral students' well-being is shaped by intrapersonal process that can be affected by interpersonal structures at the departmental level.

\section{Integration into the Scholarly Community}

The positive relationship between social membership in the academic context and perceptions of self has been previously evaluated theoretically (Lovitts, 2001) as well as empirically (Litalien \& Guay, 2015). Overall, the findings of our research supported the assumption that perceived scholarly membership is a significant negative predictor of imposter syndrome, a maladaptive psychological state characterized by the inability to accept success (in this case, academic success) as a result of one's efforts or ability, and a general perception of being unworthy of one's role as a doctoral student. Students who felt they were contributing members of their scholarly communities (e.g., research discipline, department) reported lower imposter syndrome levels, suggesting that they felt worthy of their academic positing.

Imposter syndrome and perceived belongingness can thus be viewed as two sides of the same coin; whereas those who experience imposter syndrome can feel isolated from their community due to their perceived lack of fit, perceived scholarly belongingness reflects the extent to which students feel like valued and integrated members of their departments and academic communities. Among doctoral students, it is thus plausible that feeling integrated into one's scholarly community may increase clarity of the kinds and extent of efforts required to accomplish academic 
goals thereby contributing to more realistic expectations of other's efforts and aptitudes (i.e., reduced perceptions of feeling like a fraud in comparison). It is thus not surprising that this previously theorized relationship was empirically supported in this study. As a whole, the present results highlight the role of social elements in shaping doctoral students' psychological experiences within their doctoral programs and have several significant implications for doctoral supervisors and administrators. First, the existing literature outlines how socialization effort to integrate doctoral students into their departments and scholarly communities are crucial for academic success (Lovitts, 2001) and wellbeing (Sverdlik et al., 2018). The present findings support this premise, underscoring once again the importance of perceptions of belongingness for adaptive psychological processes through doctoral education. By acknowledging the critical role of perceived social belongingness in students' well-being, faculty and administrators can establish structures to better integrate students into their scholarly communities (e.g., allocate more resources for scholarly conferences; establish and encourage paths for collaboration between members of the community), and departments can foster a supportive social atmosphere for their doctoral students that emphasizes the quality of interactions and consultation with faculty. In this regard, information sessions for departmental advisors and faculty on how to better communicate with doctoral students are encouraged, as are orientation sessions for doctoral students encouraging them to take advantage of avenues for departmental interaction and assistance. Finally, while it is important to target perceived belongingness as a determinant of such negative experiences as imposter syndrome, it is also important for future research to more specifically address the antecedents (e.g., social integration), consequences (e.g., stress, depression), and prevalence of such maladaptive self-perceptions within students themselves. For example, information sessions for first-year doctoral students could highlight the prevalence and remedies of feeling like an impostor to normalize these otherwise deleterious feelings of inadequacy. While it is possible that such interventions will not substantially reduce these experiences in doctoral students (e.g., due to persistent comparisons with more productive peers), they may nonetheless inform students that their 
feelings are not uncommon and to be expected as part of the doctoral experience. Coupled with a supportive and collegial departmental climate, such programs have the potential to enhance students' selfworth and perceived belongingness, and consequently improve doctoral students' well-being.

\section{CONCLUSIONS}

The deterioration of doctoral students' well-being is a prominent topic in conversations about doctoral education and has been increasingly gaining empirical attention in recent years. Whereas doctoral students themselves consistently identify imposter syndrome as critical to their well-being, empirical evidence on this relationship is scarce. The present research provides support for the role of imposter syndrome in shaping doctoral students' well-being. Specifically, the present findings demonstrate that imposter syndrome is a moderate to strong predictor of depression, stress, and illness symptoms cross-sectionally, as well as of changes in depression, stress, and illness symptoms over a five-month period. Moreover, imposter syndrome was found to significantly mediate the relationship between perceived belongingness and well-being; a relationship outlined in numerous studies as an important factor in doctoral students' well-being. These results imply that it is perhaps not perceived belongingness alone that contributes to doctoral students' well-being, but rather its psychological consequences, such as more adaptive selfperceptions, that protect students from the mental health concerns associated with doctoral education.

Finally, it is important to note that, although imposter syndrome did correspond with significantly more illness symptoms, it was nonetheless a stronger predictor of mental health than physical health outcomes. It is therefore important to continue exploring the role of imposter syndrome and seriously consider targeting imposter syndrome as an intervention focus for improving the mental health of doctoral students.

Two such interventions (e.g., increasing belongingness; informing first-year students of the prevalence of imposter syndrome) are outlined above, with other possible approaches including counselling services that specifically target imposter syndrome (e.g., University of British Columbia graduate workshops) and training graduate supervisors to 
identify imposter syndrome in their students and provide access to resources that can help reframe negative self-perceptions. Finally, professional development seminars that are typically taught in graduate programs could incorporate an explicit discussion of well-being topics and the prevalence of imposter syndrome, alongside other pragmatic topics (e.g., publishing protocols), to ensure that students perceive their departmental climate as supportive and, in turn, feel less like an imposter and better psychologically adjusted. Taken together, these strategies may help reduce feelings of inadequacy among doctoral students and could play a role in improving their overall psychological experiences during the doctor process.

\section{SUMMARY}

The article is devoted to the integration into the scholarly community and $\mathrm{PhD}$ imposter syndrome problem in the context of the $\mathrm{PhD}$ candidates training quality insurance. The aim of the study was to theoretically substantiate the main trends in the innovative development of doctoral education in the foreign educational discourse.

The methodology of the study is based on a systematic approach to the analysis of educational policy, which regulates the training of the applicants for degrees equivalent to $\mathrm{PhD}$. The methodological principles, the observance of which is provided by the research, include: objectivity, complexity, disclosure of contradictions of the studied subject, interdisciplinary, cultural conformity. Among the theoretical and empirical research methods prevail the following: analysis, synthesis, modeling, comparison, generalization of individual provisions of scientific approaches to substantiate the leading idea of the study, observation of the educational process, content analysis, statistical analysis.

The study found that although imposter syndrome did correspond with significantly more illness symptoms, it was nonetheless a stronger predictor of mental health than physical health outcomes. It is therefore important to continue exploring the role of imposter syndrome and seriously consider targeting imposter syndrome as an intervention focus for improving the mental health of doctoral students. 


\section{REFERENCES}

1. Adler, M. G., \& Fagley, N. S. (2005). Appreciation: Individual differences in finding value and meaning as a unique predictor of subjective well-being. Journal of Personality, 73(1), 79-114. https://doi.org/10.1111/j.1467-6494.2004.00305.x

2. Allen-Ramdial, S. A. A., \& Campbell, A. G. (2014). Reimagining the pipeline: Advancing STEM diversity, persistence, and success. BioScience, 64(7), 612-618. https://doi.org/10.1093/biosci/biu076

3. Brailsford, I. (2010). Motives and aspirations for doctoral study: Career, personal, and inter-personal factors in the decision to embark on a history PhD. International Journal of Doctoral Studies, 5, 15-27. https://doi.org/10.28945/710

4. Burt, B. A., Knight, A., \& Roberson, J. (2017). Racializing experiences of foreign-born and ethnically diverse Black male engineering graduate students: Implications for student affairs practice, policy, and research. Journal of International Students, 7(4), 925-943. https://doi.org/10.32674/jis.v7i4.182

5. Carlone, H. B., \& Johnson, A. (2007). Understanding the science experiences of successful women of color: Science identity as an analytic lens. Journal of Research in Science Teaching: The Official Journal of the National Association for Research in Science Teaching, 44(8), 11871218. https://doi.org/10.1002/tea.20237

6. Chakraverty, D. (2020). The impostor phenomenon among Black doctoral and postdoctoral scholars in STEM. International Journal of Doctoral Studies, 15, 433-460. https://doi.org/10.28945/4589

7. Di Pierro, M. (2007). Excellence in doctoral education: Defining best practices. College Student Journal, 41(2), 368-375. https://pdfs.semanticscholar.org/d50b/721b1c2a7c0689ff80a84ea2392cf 7f1abb8.pdf

8. El-Ghoroury, N. H., Galper, D. I., Sawaqdeh, A., \& Bufka, L. F. (2012). Stress, coping, and barriers to wellness among psychology graduate students. Training and Education in Professional Psychology, 6(2), 122-134. https://doi.org/10.1037/a0028768 
9. Emmioğlu, E., McAlpine, L., \& Amundsen, C. (2017). Doctoral students' experiences of feeling (or not) like an academic. International Journal of Doctoral Studies, 12, 73-90. https://doi.org/10.28945/3727

10.Etzkowitz, H., Kemelgor, C., \& Uzzi, B. (2000). Athena unbound: The advancement of women in science and technology. Cambridge University Press. https://doi.org/10.1017/cbo9780511541414

11.Evans, T. M., Bira, L., Gastelum, J. B., Weiss, L. T., \& Vanderford, N. L. (2018). Evidence for a mental health crisis in graduate education. Nature Biotechnology, 36(3), 282. https://doi.org/10.1038/nbt.4089

12. Gardner, S. K. (2013). The challenges of first-generation doctoral students. New Directions for Higher Education, 2013(163), 43-54. https://doi.org/10.1002/he.20064

13.Herzberg, F., Mausner, B., \& Snyderman, B. B. (1959). The motivation to work. New York: John Wiley \& Sons. https://doi.org/10.7202/1022040ar

14.Inouye, K., \& McAlpine, L. (2019). Developing academic identity: A review of the literature on doctoral writing and feedback. International Journal of Doctoral Studies, 14, 1-31. https://doi.org/10.28945/4168

15.Jones, M. (2013). Issues in doctoral studies-Forty years of journal discussion: Where have we been and where are we going? In Proceedings of the Informing Science and Information Technology Education Conference (pp. 83-104). Informing Science Institute. https://doi.org/10.28945/1859

16.Juniper, B., Walsh, E., Richardson, A., \& Morley, B. (2012). A new approach to evaluating the well-being of $\mathrm{PhD}$ research students. Assessment \& Evaluation in Higher Education, 37, 563-576. https://doi.org/10.1080/02602938.2011.555816

17.Knights, D., \& Clarke, C. A. (2014). It's a bittersweet symphony, this life: Fragile academic selves and insecure identities at work. Organization Studies, 35(3), 335-357. https://doi.org/10.1177/0170840613508396

18.Lovitts, B. E. (2005). Being a good course-taker is not enough: A theoretical perspective on the transition to independent research. Studies 
in Higher Education, 30(2), 137-154. https://doi.org/10.1080/ 03075070500043093

19.Lovitts, B. E. (2008). The transition to independent research: Who makes it, who doesn't, and why. The Journal of Higher Education, 79(3), 296-325. https://doi.org/10.1353/jhe.0.0006

20. McAlpine, L., Jazvac-Martek, M., \& Hopwood, N. (2009). Doctoral student experience in education: Activities and difficulties influencing identity development. International Journal for Researcher Development, 1, 97-109. https://doi.org/10.1108/1759751X201100007

21.Pallos, H., Yamada, N., \& Okawa, M. (2005). Graduate student blues: The situation in Japan. Journal of College Student Psychotherapy, 20(2), 5-15. https://doi.org/10.1300/j035v20n02_02

22. Parkman, A. (2016). The imposter phenomenon in higher education: Incidence and impact. Journal of Higher Education Theory and Practice, 16(1), 51-60. http://www.m.www.nabusinesspress.com/JHETP/ParkmanA_Web16_1_.pdf

23. Parkman, A. (2016). The imposter phenomenon in higher education: Incidence and impact. Journal of Higher Education Theory and Practice, 16(1), 51-60. http://www.m.www.na-businesspress.com/ JHETP/ParkmanA_Web16_1_.pdf

24.Pitchforth, J., Beames, S. Y., Thomas, A., Falk, M. G., Farr, A. C., Gasson, S., ... \& Mengersen, K. (2012). Factors affecting timely completion of a $\mathrm{PhD}$ : A complex systems approach. Journal of the Scholarship of Teaching and Learning, 12(4), 124-135.

25.Pyhältö, K., \& Keskinen, J. (2012). Exploring the fit between doctoral students' and supervisors' perceptions of resources and challenges vis-à-vis the doctoral journey. International Journal of Doctoral Studies, 7, 395-414. https://doi.org/10.28945/1745

26. Russell, M. L., \& Atwater, M. M. (2005). Traveling the road to success: A discourse on persistence throughout the science pipeline with African American students at a predominantly white institution. Journal of Research in Science Teaching, 42(6), 691-715. https://doi.org/10.1002/tea.20068

27. Schmidt, M., \& Hansson, E. (2018). Doctoral students' wellbeing: a literature review. International Journal of Qualitative Studies on 
Health and Well-being, 13, 1508171. https://doi.org/10.1080/ 17482631.2018.1508171

28.Sonnak, C., \& Towell, T. (2001). The impostor phenomenon in British university students: Relationships between self-esteem, mental health, parental rearing style and socioeconomic status. Personality and Individual Differences, 31(6), 863-874. https://doi.org/10.1016/s01918869(00)00184-7

29. Stone, S., Saucer, C., Bailey, M., Garba, R., Hurst, A., Jackson, S. M., ... \& Cokley, K. (2018). Learning while Black: A culturally informed model of the impostor phenomenon for Black graduate students. Journal of Black Psychology, 44(6), 491-531. https://doi.org/10.1177/ 0095798418786648

30.Sverdlik, A., \& Hall, N. C. (2019). Not just a phase: Understanding the role of doctoral program stage on motivation and well-being. Journal of Adult and Continuing Education, 26(1), 97-124. https://doi.org/10.1177\%2F1477971419842887

31. Trenberth, L. (2005). The role, nature and purpose of leisure and its contribution to individual development and well-being. British Journal of Guidance and Counselling, 33(1), 1-6. https://doi.org/10.1080/03069880412331335849

32. University of California, Berkeley. (2005). Berkeley Graduate Student Mental Health Survey. In Report of the University of California Student Mental Health Committee, Appendix E. https://regents.universityofcalifornia.edu/regmeet/sept06/303attach.pdf

33. University of California, Berkeley. (2014). The Graduate Assembly: Graduate Student Happiness \& Well-Being Report. http://ga.berkeley.edu/wpcontent/uploads/2015/04/wellbeingreport_2014.pdf

34. World Health Organization. (2017). Depression and other common mental disorders: Global health estimates. http://apps.who.int/iris/bitstream/10665/254610/1/WHO-MSD-MER2017.2-eng.pdf

35. Wyatt, T., \& Oswalt, S. B. (2013). Comparing mental health issues among undergraduate and graduate students. American Journal of 
Health Education, 44(2), 96-107. https://doi.org/10.1080/ 19325037.2013.764248

Information about the authors: Boychuk P. M., Candidate of Pedagogical Sciences, Associate Professor, Rector, Municipal Higher Educational Institution "Lutsk Pedagogical College" of the Volyn Regional Council 36 Voli ave., Lutsk, Volyn region, 43010, Ukraine

Fast O. L.,

Candidate of Pedagogical Sciences, Associate Professor, Vise-rector on Research, Teaching and International Relations, Municipal Higher Educational Institution "Lutsk Pedagogical College" of the Volyn Regional Council 36 Voli ave., Lutsk, Volyn region, 43010, Ukraine

Martyniuk A. P.,

Candidate of Pedagogical Sciences, Associate Professor, Head of the Department of Ukrainian and Foreign Philology, Lutsk National Technical University 75 Lvivska str., Lutsk, Volyn region, 43000, Ukraine 